$\mathbf{R}_{\text {ESEARCH }} \mathbf{P}_{\text {APER }} \longrightarrow \frac{\text { FOOD SCIENCE. }}{\text { RESEARCH JOURAL }}$

\title{
Spirulina as super food: Product enrichment
}

\author{
Kiran Agrahari and Shabnam Jahan
}

\begin{abstract}
The objective of present investigation "Spirulina as super food: Product Enrichment" was to standardize and develop the products using spirulina powder and their organoleptic evaluation. Dried Spirulina contains 5\% water, 24\% carbohydrates, $8 \%$ fat, and about $60 \%(51-71 \%)$ protein. It is a complete protein source containing all essential amino acids, provided in its typical supplement form as a dried powder, a 100 gram amount of spirulina supplies 290 Calories and is a rich source of numerous essential nutrients, particularly B vitamins and dietary minerals, such as iron and manganese. The lipid content of spirulina is $8 \%$ by weight providing the fatty acids, gamma-linolenic acid, alpha-linolenic acid, linoleic acid, stearidonic acid, eicosapentaenoic acid, docosahexaenoic acid, and arachidonic acid.Spirulina benefits are so amazing that taken on a daily basis.They could restore and revitalize health such as detoxes heavy metals (especially arsenic), improve HIV/AIDS, prevent cancer, lower blood pressure, reduce cholesterol and speed up weight loss. Developed products of spirulina powder were biscuit and smoothie. The organoleptic evaluation of products was done by using (9Point hedonic scale). The result of spirulina powder based products for biscuit, smoothie $\left(T_{1}\right)$ and $\left(T_{2}\right)$ were best in all treatments in case of all sensory attributes. The overall acceptability of experimental $\left(\mathrm{T}_{1}\right)$ and $\left(\mathrm{T}_{2}\right)$ spirulina biscuit and smoothie were 8.0, 8.5 and 8.5, 9, respectively. Developed products were accepted by panel members.
\end{abstract}

Key Words : Spirulina powder, Super food, Enrichment, Products

How to cite this article : Agrahari, Kiran and Jahan, Shabnam (2018). Spirulina as super food: Product enrichment. Food Sci. Res. J., 9(1): 194-197, DOI : 10.15740/HAS/FSRJ/9.1/194-197.

\section{INTRODUCTION}

Spirulina represents a biomass of cyanobacteria (blue-green algae) that can be consumed by humans and other animals. There are two species, Arthrospira platensis and Arthrospira maxima.The maxima and platensis species were once classified in the genus spirulina. The common name, spirulina, refers to the dried biomass of Arthrospira platensis, which belongs to the oxygenic photosynthetic bacteria that cover the groups cyanobacteria and prochlorales. The major protein in

\section{MEMBERS OF RESEARCH FORUM}

Author for correspondence :

Shabnam Jahan, Kamla Nehru Institute of Physical and Social Science, Sultanpur (U.P.) India

(Email : shabnamsln035@gmail.com)

Associate Authors' :

Kiran Agrahari, Kamla Nehru Institute of Physical and Social Science, Sultanpur (U.P.) India spirulina is phycocyanin which is a deep blue color pigment and about $150 \mathrm{mg}$ of it is present in $1 \mathrm{~g}$ of spirulina. Spray dried spirulina is rich in proteins. Vitamins particularly $\beta$ carotene and gamma linolenic acid. Provided in its typical supplement form as a dried powder, a $100 \mathrm{~g}$ amount of spirulina supplies 290 Calories and is a rich source of numerous essential nutrients, particularly $B$ vitamins and dietary minerals, such as iron and manganese (Table A). The quality of protein of spirulina is better than cereal and soya proteins (Brill, 2006). About $70 \% \beta$-carotene is absorbed. One gram spirulina contains carotenoids equivalent to $1 \mathrm{~kg}$ of vegetables and yellow fruits. Spirulina is many times richer in iron, vitamin A, thiamine, riboflavin, nicotinic acid and vitamin B12 compared to milk and egg. Chlorophyll present in spirulina is a detoxifying phytonutrient. Spirulina apart from being rich in nutrients contains phytonutrients like, gamma linolenic acid, sulpholipid, phoycocyanin and antioxidant vitamin. Freshly 